\section{EMBRYRIDDLE \\ Aeronautical University}

SCHOLARLY COMMONS
International Journal of Aviation, Aeronautics, and Aerospace

\title{
AERODYNAMIC PERFORMANCE ANALYSIS OF CO-FLOW JET AIRFOIL
}

\section{M Vigneswaran}

Research Scholar, School of Aeronautical Science, Hindustan Institute of Technology and Sciences (HITS), Chennai, CMVIGNESWARANAERO@GMAIL.COM

Vishnu Kumar G C Asistant Professor, School of Aeronautical Science, Hindustan Institute of Technology and Sciences (HITS), Chennai, gcvkumar@hindustanuniv.ac.in

Follow this and additional works at: https://commons.erau.edu/ijaaa

Part of the Aerodynamics and Fluid Mechanics Commons

\section{Scholarly Commons Citation}

Vigneswaran, C., \& Kumar G C, V. (2021). AERODYNAMIC PERFORMANCE ANALYSIS OF CO-FLOW JET AIRFOIL. International Journal of Aviation, Aeronautics, and Aerospace, 8(1). https://doi.org/10.15394/ ijaaa.2021.1555

This Article is brought to you for free and open access by the Journals at Scholarly Commons. It has been accepted for inclusion in International Journal of Aviation, Aeronautics, and Aerospace by an authorized administrator of Scholarly Commons. For more information, please contact commons@erau.edu. 
Vigneswaran and Kumar G C: AERODYNAMIC PERFORM ANCE ANALYSISOF CFJ AIRFOIL

The cross-sectional area of a wing is a major factor in the production of lift, as an airfoil. Overall lift production is calculated by the 3D shape of the wing. The landing and takeoff phases required a maximum value of $\mathrm{C}_{1}$ to reduce the takeoff and landing distance. A wing with a high span provides more lift during the takeoff and landing phases; it helps for reducing the takeoff and landing distances, but it has its own structural and maneuver problem. A wing with less span is more effective at cruise but it fails to provide the required performance during takeoff and landing. To overcome the small wing problems during takeoff/landing, it can be fitted with high lift devices or can utilize the flow control.

Various flow control methods have been presented to date. Implementing the flow control to an airfoil avoids the separation occurrence and a thin boundary layer remains attached with the body which prevents the pressure drop at the trailing edge. As a result, it reduces the drag to reach its minimum and increase the lift to its maximum.

The co-flow jet (CFJ) is a relatively modern active flow control method that was proposed by Zha and Paxton (2004). The co-flow jet airfoil has an injection slot and suction slot near the leading edge and the trailing edge of the airfoil suction surface. The slots are opened by translating a large portion of the suction surface downward. A high-energy jet is then injected near the leading edge tangentially and the same amount of mass flow is sucked in near the trailing edge. The CFJ airfoil is a zero-net mass flux (ZNMF) flow control technique, meaning that it does not involve additional mass flow into the system, i.e., the mass flow which is sucked into the suction slot is equal to the mass flow which is pressurized and pumped-out through the injection slot. Due to the injection slot present in the CFJ airfoil, it causes the main flow to be attached particularly at high angles of attack and it provides the energy to resist the adverse pressure gradient. A suction slot contributes to reaching the zero net jet mass flow rate.

\section{Literature Review}

Zha et al. (2006) experimentally investigated the effects of CFJ on NACA 0025 airfoil at the low Reynolds number and results indicated that the airfoil with CFJ gives the maximum lift compared to the baseline airfoil. The authors conducted the computational analysis using numerical methods and attempted to match with the experimental value. They came up with the new dimensionless parameter called jet momentum coefficient and they investigated the performance of CFJ airfoil by using the momentum coefficient. Later, Zha et al. (2007) conducted the numerical and experimental analysis on CFJ airfoils to investigate the effect of injection slot size on the performance of CFJ airfoil. Then they carried out the analysis to investigate the jet mechanism of co flow jet airfoil. For all, the results indicated that the lift coefficient and stall AoA increased relatively. 
Hossain et al. (2015) conducted experiments in the wind tunnel on NACA 0015 and they compared it with CFJ0015-065-065 airfoil. A vacuum pump and compressor are used to suck the air in the suction slot and to inject the air at a mass flow rate of $0.03 \mathrm{~kg} / \mathrm{s}$ in the injection slot. The suction pressure was controlled by wheel valve whereas the flow meter was used to measure the mass flow rate of injection air. This paper concluded that the CFJ airfoil significantly increased the lift coefficient by $82 \%$ and reduced the drag by $16.5 \%$ compared to the baseline airfoil.

Siddanathi (2016) performed the experimental investigation on NACA 652-415 and compared it with CFJ airfoil. The result of this experimental study showed that the lift coefficient of CFJ airfoil is increased by a factor of 5 and the drag coefficient is reduced by a factor 3. And also, this paper investigated the effect of jet velocity on CFJ performance. The results indicated that for a constant freestream velocity, the lift coefficient is maximum only for an optimum threshold jet velocity. At that jet velocity, the CFJ airfoil effectively reduces the power consumption of the pump.

Ethiraj (2017) carried out the numerical analysis on NACA 63-015-065142 CFJ wing and compared the results with the baseline NACA 63-015 wing having a span length of $2 \mathrm{~m}$ and a chord length of $1 \mathrm{~m}$. 3D compressible RANS equation wasused for an analysis. This paper concluded that the lift coefficient is increased by 20 percent and the drag coefficient is decreased 30 percent.

Abinav et al. (2016) performed the numerical analysis on the NACA 6409 airfoil and it compared with CFJ airfoil. The results show that there is a significant percentage of increment in lift coefficient and stall margin compared to the baseline airfoil. Also, this paper suggests placing the injection and suction slot with sufficient distance for complete mass conservation and to improve the aerodynamic coefficients.

Khoshnevis et al. (2020) numerically investigated the performance of CFJ airfoil with five different moderate Reynolds number. The results interpreted that the lift coefficient of CFJ airfoil is increased with an increase in the coefficient of momentum. As soon as the coefficient of jet momentum exceeds the threshold limit, the performance of CFJ airfoil decreased.

Balaji et al. (2020) conducted the experimental investigation of a Modified CFJ (MVCJ) airfoil and it compared with baseline airfoil. The modified CFJ had a CD nozzle on the injection slot to reduce the work of the pump. This paper concluded that the lift coefficient is increased by $43 \%$ as compared to baseline airfoil.

\section{Governing Equation}

\section{Governing Equation Turbulence Model}

To examine the velocity and pressure distributions in a flow field, the 
conservation of mass and momentum equations must be solved under the existing boundary conditions. The equation for conservation of mass and momentum can be written as follows:

$$
\begin{aligned}
& \frac{\partial \rho}{\partial t}+\Lambda \cdot(\rho \hat{v})=0 \\
& \frac{\partial}{\partial t}(\rho \hat{v})+\Lambda \cdot(\rho \hat{v} \hat{v})=-\Lambda p+\Lambda \cdot r+\rho g+F
\end{aligned}
$$

In the above equation $\rho$ - density, $\mathrm{p}$ - static pressure, $\mathfrak{r}$ - stress tensor, $\rho g-$ gravitational force; F- external body force.

\section{Turbulence Model}

\section{Splarat-Allmaras Model}

This model is a one equation model for turbulent viscosity and it solves just one transport equation for viscosity; Spalart-Allmaras is a low-cost RANS model solving a transport equation for a modified eddy. In particular, it gives good results in the flow around the airfoil.

$\frac{\partial}{\partial t}(\rho \hat{v})+\frac{\partial}{\partial \mathbf{x} \mathbf{j}}\left(\rho \hat{v} u_{i}\right)=G_{v}+\frac{1}{\sigma \hat{v}}\left[\frac{\partial}{\partial t}\left[\left\{(\mu+\rho v) \frac{\partial \hat{v}}{\partial \mathbf{x} \mathbf{j}}\right)\right\}+\left(C_{b 2} \rho \frac{\partial \hat{v}}{\partial \mathbf{x} \mathbf{j}}\right)\right]-Y v(2.2 .1)$

In equation (2.2.1) $\hat{v}$ - turbulence kinematic viscosity, $G_{v}$ - turbulence production, Yv-turbulence destruction; $\sigma_{v}$ and $C_{b 2}$ - indicate constants.

\section{NACA 0018 Airfoil}

\section{Baseline Airfoil}

The NACA 0018 airfoil is symmetrical, the 00 indicating that it has no camber, it is $18 \%$ as thick as it is long. The model is created using CATIA V-5. The model is then imported into the meshing software, i.e., ICEM CFD. Theoretically, the far field should be at least 10 times the chord length. So, the diameter of the far field is 100 times more than the chord, with its center at the mid-point of the chord of the airfoil. The chord of the airfoil is $283 \mathrm{~mm}$. To solve the flow solution, an O-type structured grid is used. As it can be observed, the nodes possess an appropriate perpendicular to one another. To investigate grid independency of the computational domain, the mesh with different numbers of nodes such as 1.2 lakhs, 1.8 lakhs, and 2.3 lakhs are generated. It is necessary to validate the flow solver using to analyze the problem. So, the experimental data obtained by Jacobs and Sherman (1937; National advisory committee for aeronautics, report no 586) were used to evaluate the solver ability. Y-plus is maintained in near 1 to effectively capture the boundary layer phenomenon. Spalart-Allmaras turbulence model is employed for analysis. This baseline airfoil is then analyzed at Mach 0.1 , for sea-level conditions with a Reynolds number of 6.54 lakhs. This Mach number is assumed to be the average take-off or landing Mach number for a wide range of aircraft. Figure 1 shows the comparison of aerodynamic coefficients of baseline airfoil with the experimental result. And it can be observed that there is an acceptable agreement between the numerical and experimental values. 
Figures 1 and 2 show a comparison of aerodynamic coefficients of baseline airfoil with different grid size and experimental result (a) Lift coefficient vs AoA (b) Drag coefficient vs AoA.

\section{Figure 1}

\section{Lift Coefficient vs AoA}

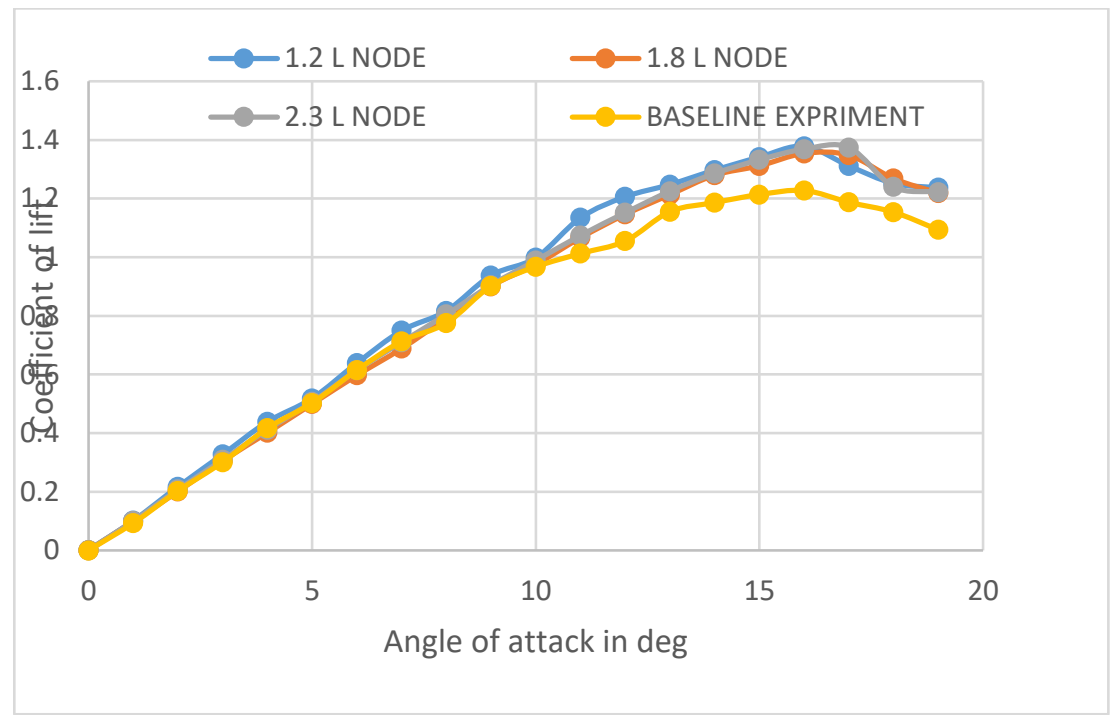


Figure 2

Drag Coefficient vs AoA

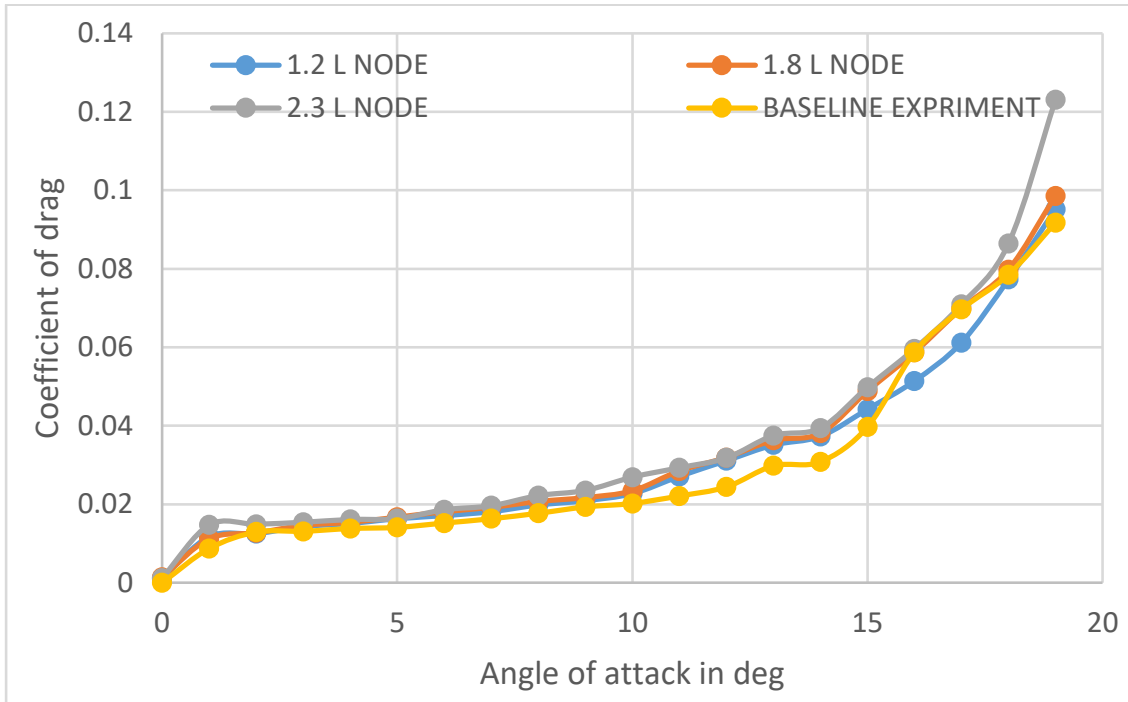

\section{CFJ Airfoil}

CFJ boundary condition assumes subsonic inflow and subsonic outflow in the injection and suction cavities respectively. To achieve zero-net mass-flux with the CFJ flow control, the mass flow that exits the injection slot must equal the mass flow entering the suction slot. To do this, the static pressure at the suction slot entrance is iterated to match the injection jet mass flow rate. The model is created using CATIA V-5. The model is then imported into the meshing software, i.e., ICEM CFD. The mesh size at wall boundaries is much finer than further out in the flow field. O-gird topology mesh is generated. The blocks near the airfoil are coarse-meshed and maintaining y-plus around 1 near the walls of the airfoil to effectively capture the boundary layer. The computational domain and boundary conditions around the CFJ airfoil is shown in Figure 3. 


\section{Figure 3}

\section{The Computational Domain and Boundary Conditions Around the CFJ Airfoil}
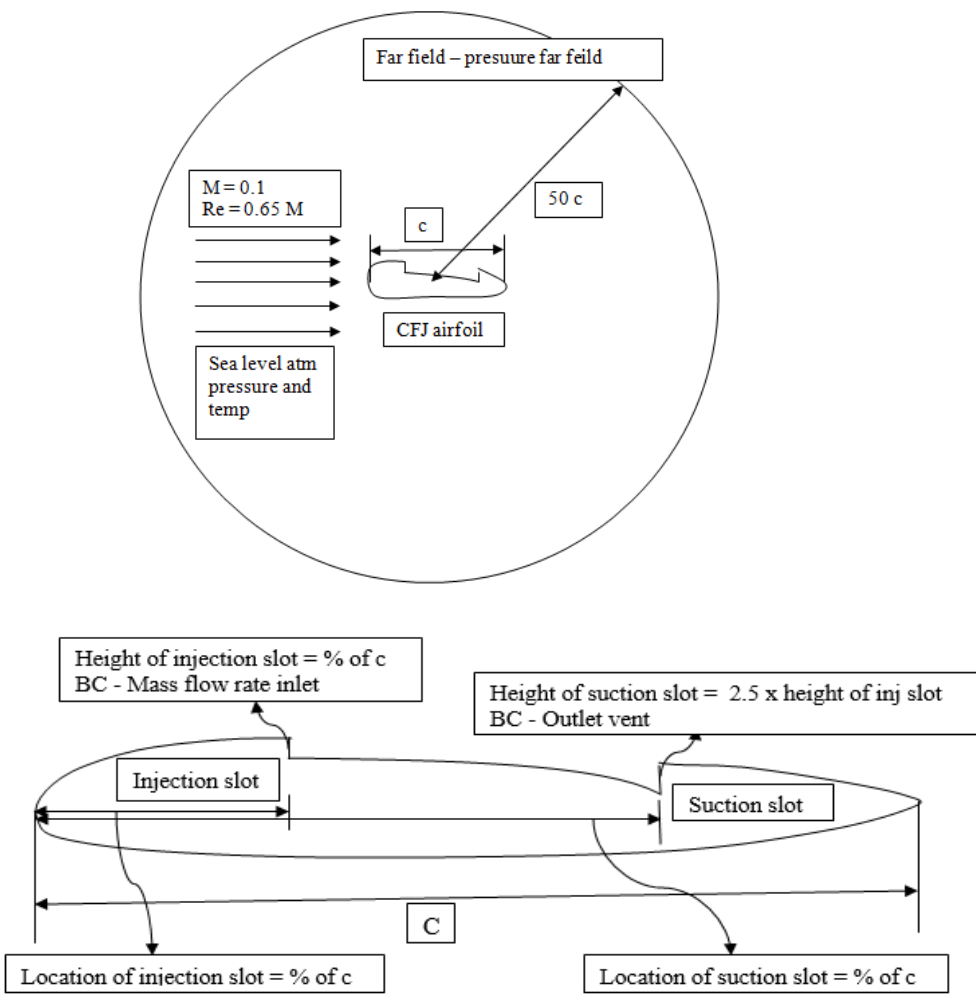

To carry forward the CFD analysis of CFJ airfoil, the first gridindependent study has to be done. To investigate the grid independency of the computational domain, meshes with different numbers of nodes such as $50 \mathrm{k}, 1$ lakhs, 1.6 lakhs, and 2.2 lakhs are generated for the following design specification. Height of suction slot designed two and half times more than injection slot height to reduce the suction pressure value to suck the same mass flow rate of air. Figure 4 shows the $\mathrm{O}$ grid topology used in flow computation and the location of injection and suction slot on CFJ airfoil.

Chord length of CFJ airfoil: $283 \mathrm{~mm}$

Location of Injection Slot: $9 \%$ of the Chord

Location of Suction Slot: $82 \%$ of the Chord

Height of the Injection Slot: $0.75 \%$ of the Chord

Height of the Suction Slot: 2.5 x Height of the Injection Slot 


\section{Figure 4}

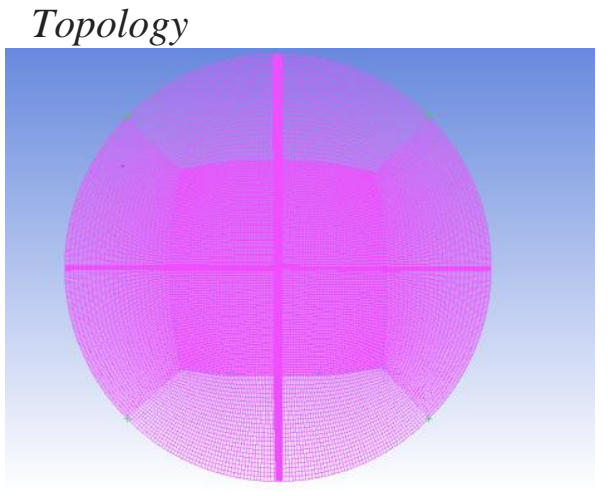

Fig.4 (b) Near field

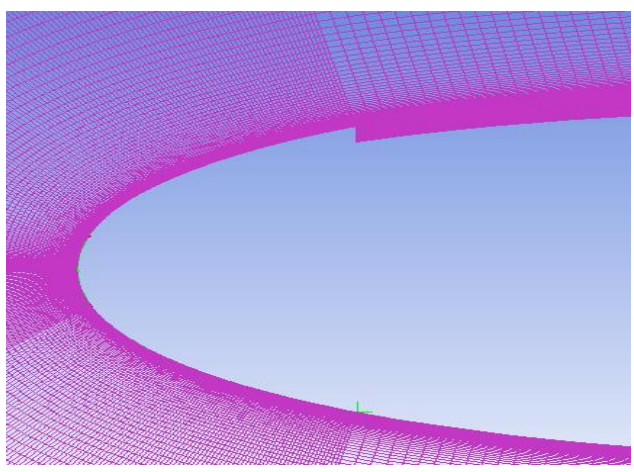

Fig.4 (c) injection slot

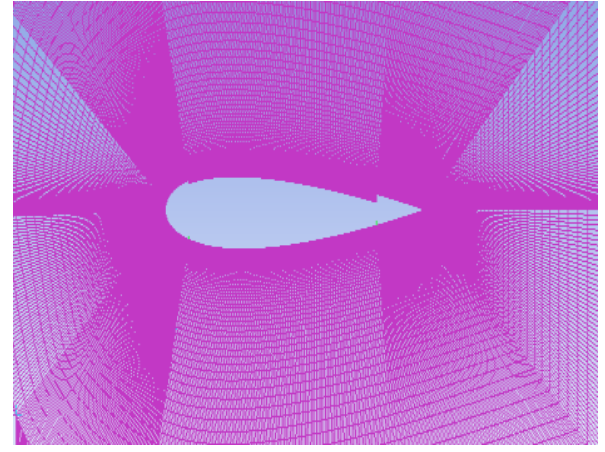

Fig.4 (a) Far field

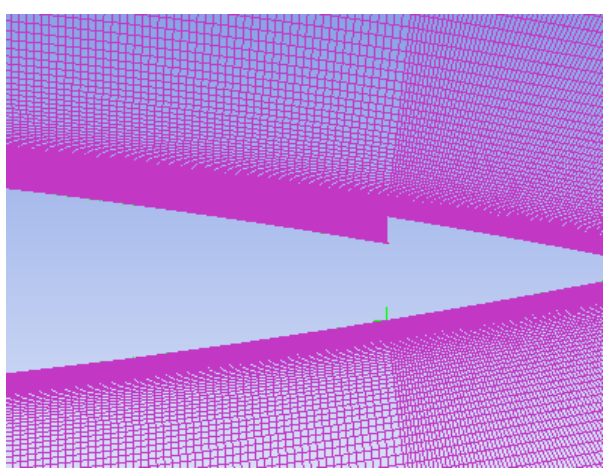

Fig.4 (d) suction slot

Note. The $\mathrm{O}$ grid topology mesh used in flow computation. (a) Far field (top left), (b) Near field (top right), (c) injection slot (down left), and (d) suction slot (down right).

The numerical analysis is carried out in a FLUENT solver for sea level boundary conditions at 0.1 Mach number and 0.65 million Reynolds number. RANS equation solved for 2D incompressible and unsteady flow. SpalartAllmaras turbulence model is employed for analysis. Y-plus is maintained near the airfoil surface as 1 to effectively capture the boundary layer phenomenon. Additional boundary conditions required for the analysis of CFJ airfoils are given as follows: the injection slot is given as 'mass flow inlet' and the mass flow rate is chosen as $0.15 \mathrm{~kg} / \mathrm{s}$ and the suction slot is given as 'outlet vent.' To maintain the ZNMF, static pressure at the suction slot has to be iterated to match the injection mass flow rate. Figure 5 shows the aerodynamic coefficients vs the Angle of attack curve for the four different grid sizes. From the analysis, it verified that, if the grid around the airfoil is more than 1.6 lack nodes, then the aerodynamic parameters are constant compares to the lower grid size. The grid size with 2.2 
lakh nodes was selected to conduct the numerical analysis for the further design. And also from the analysis, it's proved that the CFJ airfoil will increase the coefficient of lift significantly compare to the baseline airfoil. Figure 6 shows the pressure and velocity contour at stalling angle for the 2.2 lakhs node grid size. Further, this paper investigates the aerodynamic performance of CFJ airfoil for the varying injection and suction slot location keeping the boundary. Figures 5 a and $b$ show the comparison of lift coefficient and drag coefficient of the CFJ airfoil for the four different mesh size; (a) Lift coefficient vs AoA (b) Drag coefficient vs AoA

\section{Figure 5(a)}

\section{Lift Coefficient vs AoA}

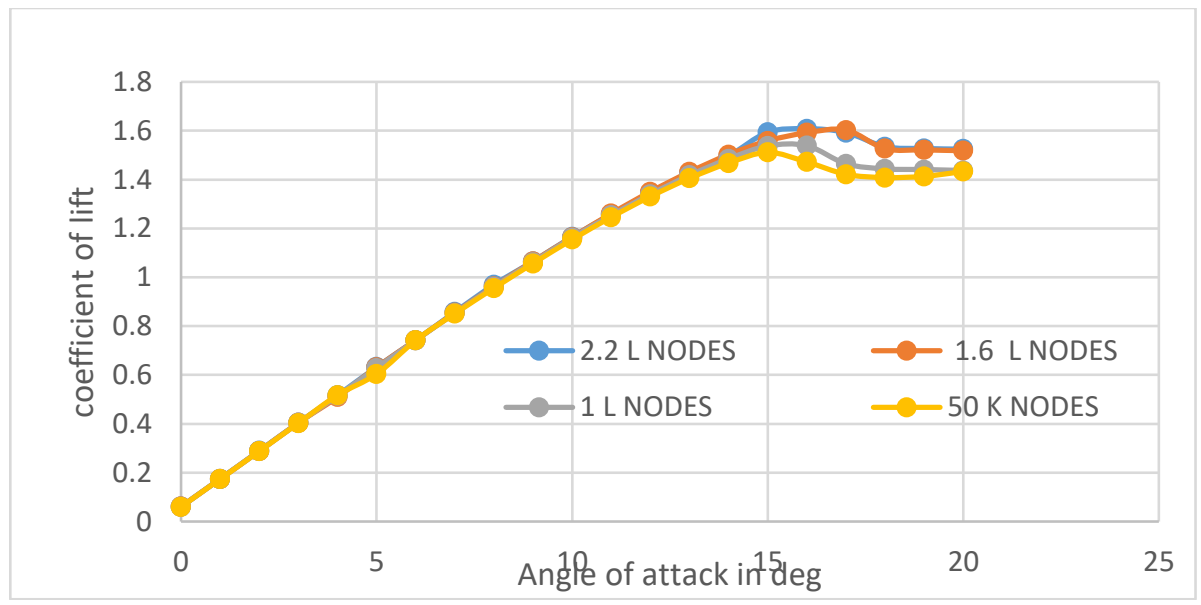


Figure 5(b)

Drag Coefficient vs AoA

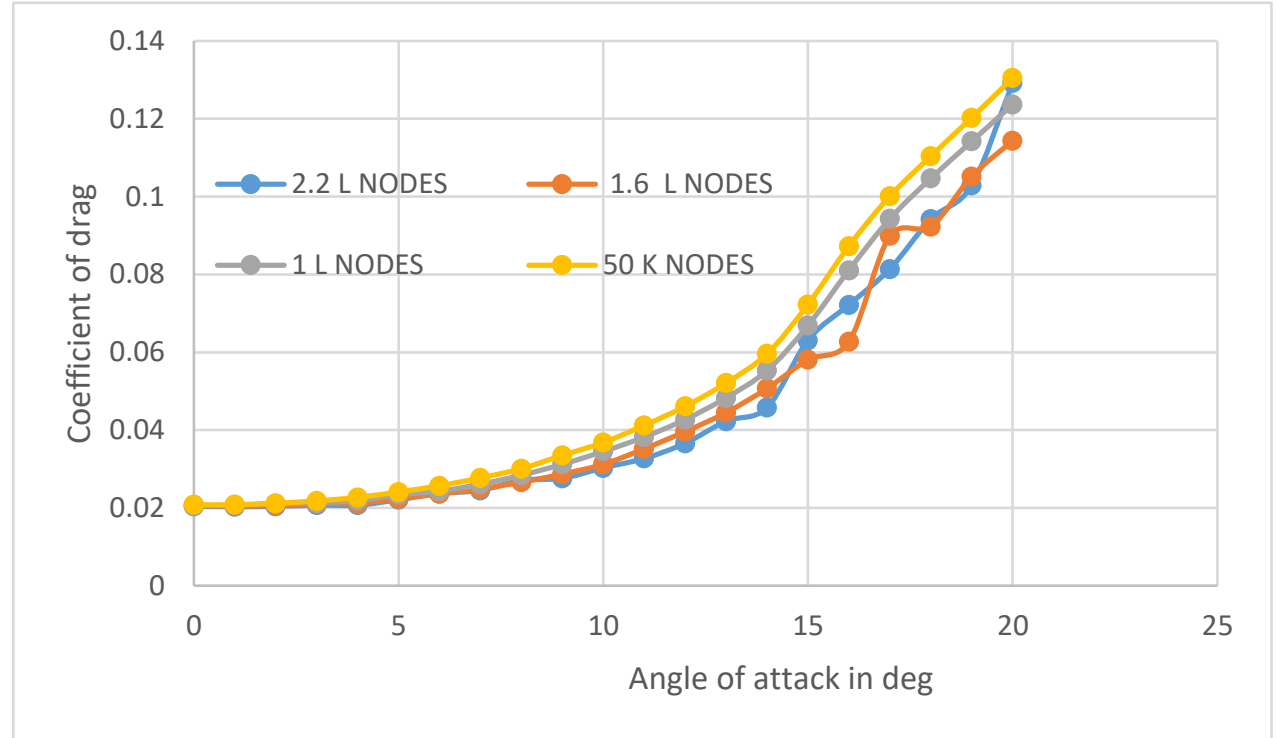

Figures 6 a through d show: (a)Velocity contour (top left), (b) pressure contour (top right), (c) velocity vector near injection slot (down left) and (d) velocity vector near suction slot (down right) of CFJ airfoil at stalling angle of attack $\left(16^{\circ}\right)$ for the 2.2 lakhs node grid size.

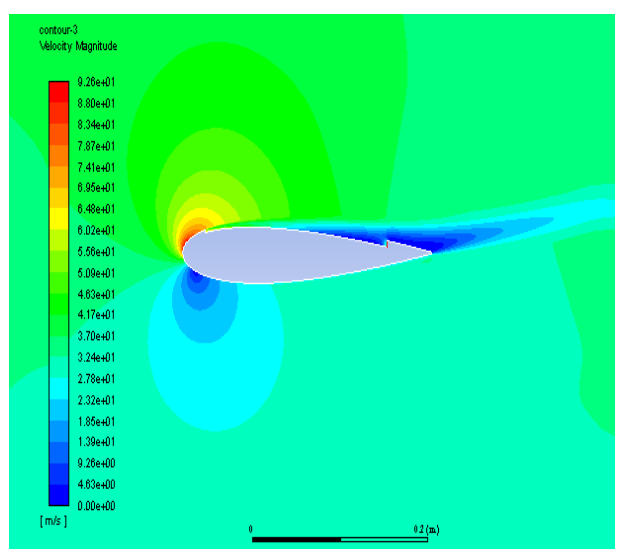

Figure 6 (a) Velocity contour

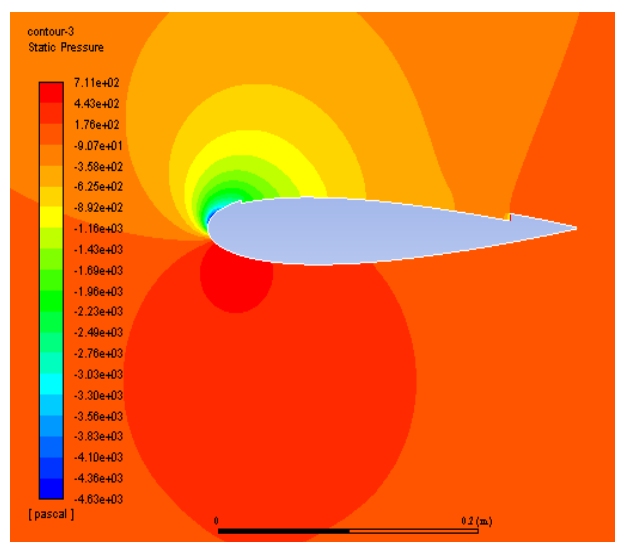

Figure 6 (b) Pressure contour 


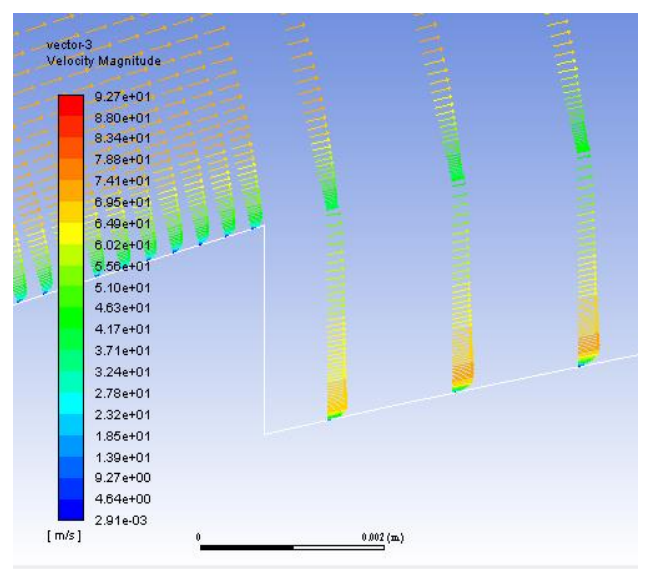

(c) Velocity vector near injection slot

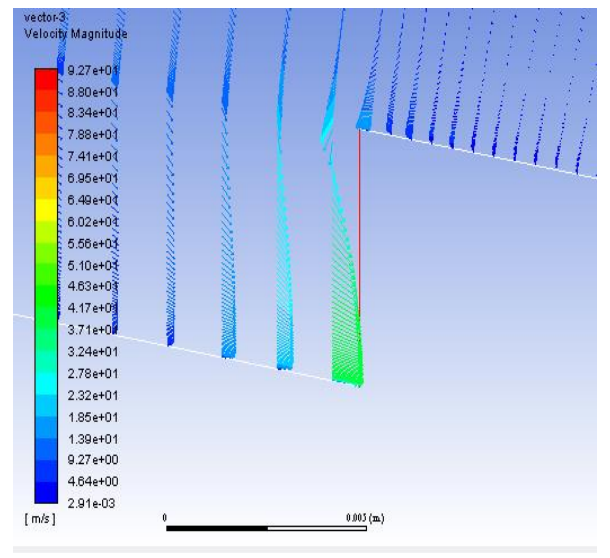

(d) Velocity vector near suction slot

\section{Evaluation of CFJ Performance on Aerodynamic Coefficients}

In this section, the investigation is carried out for the following design specifications of CFJ airfoil for an AoA range of $0^{\circ}-20^{\circ}$. A main aim of the present study to evaluating the aerodynamic performance of CFJ airfoil for different injection and suction slot location and also to optimize the injection and suction slot location by considering the other specifications and boundary condition remains same.

Chord length of CFJ airfoil: $283 \mathrm{~mm}$

Location of Injection Slot: varying from $6 \%$ to $13 \%$ of the Chord by unit increment

Location of Suction Slot: $82 \%$ of the Chord

Height of the Injection Slot: $0.75 \%$ of the Chord

Height of the Suction Slot: $2.5 \mathrm{x}$ Height of the Injection Slot

Figure 7 shows the lift coefficient and drag coefficient of CFJ airfoil for all design specifications (varying injection slot location from $6 \%$ to $13 \%$ of a chord and suction slot fixed at $82 \%$ of c). From the analysis, it proved that the CFJ airfoil is increasing lift compare to the baseline airfoil. It is due to the flow over a CFJ airfoil gets energized by the injection air. So that, the flow remains attached to the body, that's delays the boundary layer separation. And also the graph shows that varying the location of the injection slot from the leading edge is leads to an increase in the lift coefficient of CFJ airfoil. The reason behind this is; While implementing the CFJ mechanism to baseline airfoil, the upper surface gets translate vertically downward. Because of this, the aerodynamic shape of the CFJ airfoil is comparably varied from the baseline airfoil. So, the lift coefficient due to the aerodynamic shape of the CFJ airfoil is may lesser than the baseline airfoil. But once the CFJ mechanism gets activate to the CFJ airfoil, the increase in lift 
coefficient due to the CFJ mechanism overcomes the decrease in lift coefficient due to the aerodynamic shape of the CFJ airfoil. Overall, the lift coefficient from the CFJ airfoil is higher than the baseline airfoil. As long as, the CFJ airfoil shape remains close to the baseline airfoil shape, it will enhance the aerodynamic coefficients of the CFJ airfoil. Once the injection slots get vary from $6 \%$ to $13 \%$ of chord, the aerodynamic shape of the CFJ airfoil is also varying accordingly. So, it leads to an increase in the lift coefficient additional to the effect of injecting air from the injection slot. And it's very clear from the analysis that injecting the air from the injection slot is playing a vital role in increasing of lift coefficient and the production of lift coefficient due to the CFJ mechanism has to overcome the decreasing of lift coefficient due to the aerodynamic shape of the CFJ airfoil. Overall, from the analysis, this study concludes that CFJ airfoil performing well to increase the lift coefficient, and also the varying the injection slot from $6 \%$ to $13 \%$ of a chord for a suction slot at $82 \%$ of $\mathrm{c}$ is leads to an increase in the lift coefficient. A Percentage of increase in maximum lift coefficient of CFJ airfoil compares to the baseline airfoil is varies from $3.6 \%$ to $31.9 \%$ for an injection slot location varies from $6 \%$ to $13 \%$ of chord and suction slot at $82 \%$ of chord. Moreover, if the injection slot placed beyond $13 \%$ percent of a chord, there may be a chance of increase or decrease in lift coefficient but that is out of interest of this study because keeping the structural aspect of the wing into consideration, it's not advisable to place the injection slot far away from the leading edge of an airfoil. Usually, the front spar is designed to locate on $15 \%$ to $25 \%$ of the chord. So considering the structural complexity into the account, this work is suggesting that placing the injection slot in between $6 \%$ to $15 \%$ of the chord will be feasible.

Figure 7(a)

\section{Lift Coefficient vs AoA}

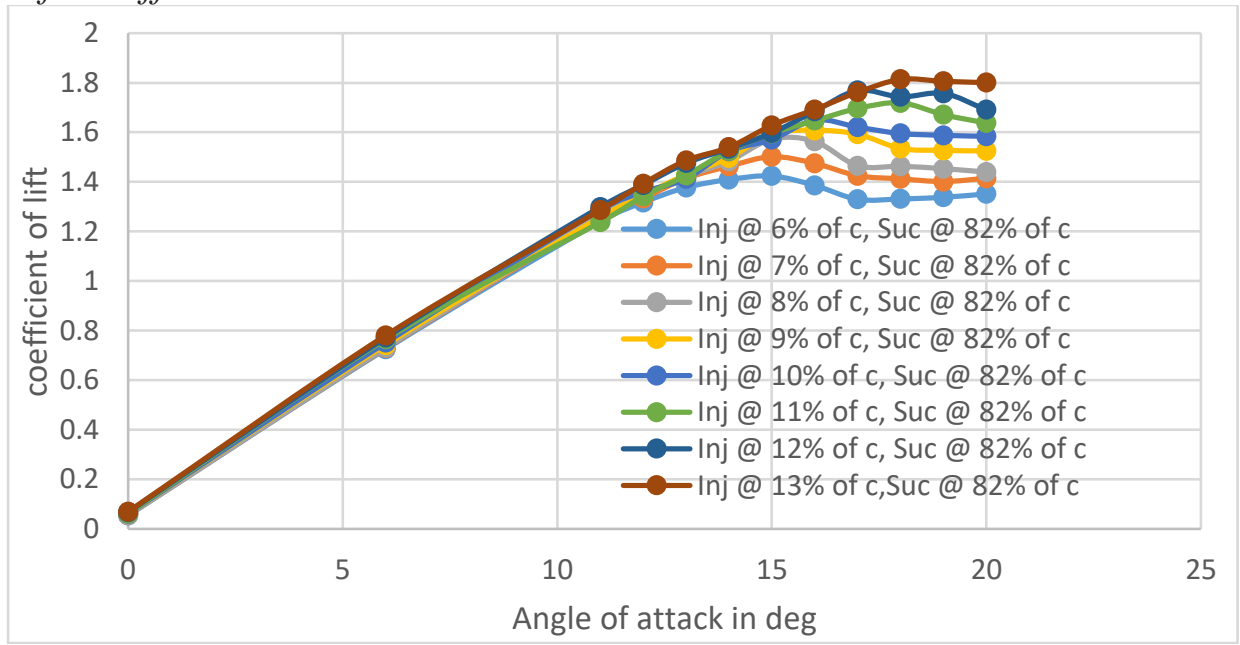


Figure 7(b)

Drag Coefficient vs AoA

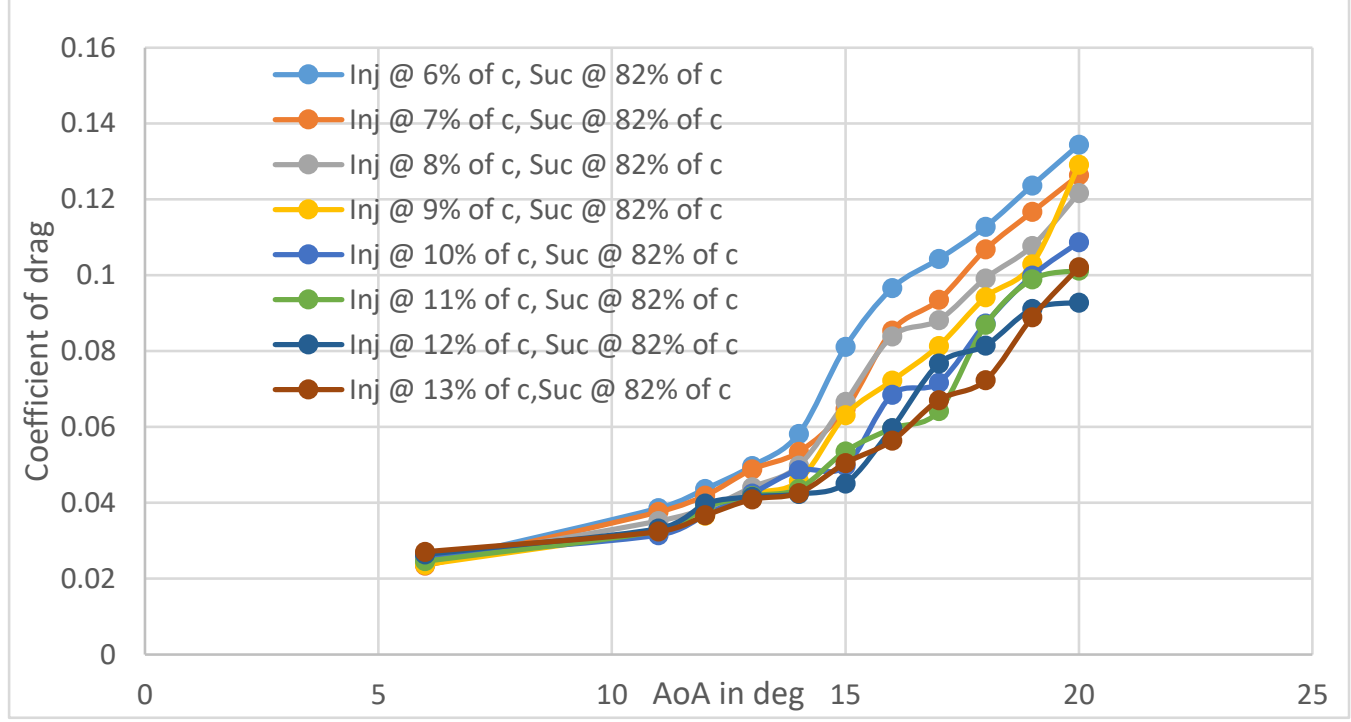

Note. The comparison of Lift coefficient and Drag coefficient of CFJ airfoil for all design specification (varying injection slot location from $6 \%$ to $13 \%$ of chord and suction slot at $82 \%$ of c). (a) Lift coefficient vs AoA (b) Drag coefficient vs AoA.

To get a better understanding of the effect of CFJ, again the investigation is carried out for following design specification of CFJ airfoil. Here, the location of the suction slot is shifted to $85 \%$ of the chord and the location of the injection slot is varying from $6 \%$ to $13 \%$ of the chord with keeping other design specification and boundary conditions remains the same as described above.

Location of Injection Slot: varying from $6 \%$ to $13 \%$ of the Chord by unit increment

Location of Suction Slot: $85 \%$ of the Chord

Height of the Injection Slot: $0.75 \%$ of the Chord

Height of the Suction Slot: 2.5 x Height of the Injection Slot

Figure 8 illustrates the lift coefficient and drag coefficients of CFJ airfoil for all design specifications (varying injection slot location from $6 \%$ to $13 \%$ of chord and suction slot at $85 \%$ of the chord). The results from this analysis are saying that varying the location of the injection slot from $6 \%$ to $13 \%$ of the chord for the suction slot location at $85 \%$ of $\mathrm{c}$ is increasing the value of maximum lift coefficient and it's adding strength to the statement discussed in the above analysis. A percentage of increase in maximum lift coefficient of CFJ airfoil compares to the baseline airfoil is varies from $2.58 \%$ to $29.3 \%$ for an injection slot location varies from $6 \%$ to $13 \%$ of chord and suction slot at $85 \%$ of chord. In 
another aspect, if the suction slot shifted from $82 \%$ of $\mathrm{c}$ to $85 \%$ of $\mathrm{c}$, the maximum lift coefficient starts to decreasing for the fixed injection slot location. For example, the suction slot locates at $82 \%$ of the c is generate a lift coefficient $2.58 \%$ higher than the suction slot locates at $85 \%$ of the $\mathrm{c}$, for the injection slot at $13 \%$ of c. Figure 9 shows the comparison of lift coefficient for the injection slot at $13 \%$ of the chord and suction slot at $82 \%$ and $85 \%$ of the chord. So, it is very clear from the analysis that the suction slot is not only meant to reach the zero net mass flow rate, also, it's playing an important role in CFJ performance. On one hand, if the suction slots move towards the trailing edge, it's reducing the performance of the CFJ airfoil. On the other hand, if it moves towards the leading edge or if it moves towards the injection slot, the performance of the CFJ airfoil is increasing. To reduce the workload of the pump or to reduce the power consumption of the pump, the suction slot has to locate at the airfoil where the pressure of the flow over the top surface of the airfoil is maximum. In addition, there should be a minimum optimal distance is required between injection and suction slot to conserve the mass flow rate.

\section{Figure 8(a)}

\section{Lift Coefficient vs AoA}

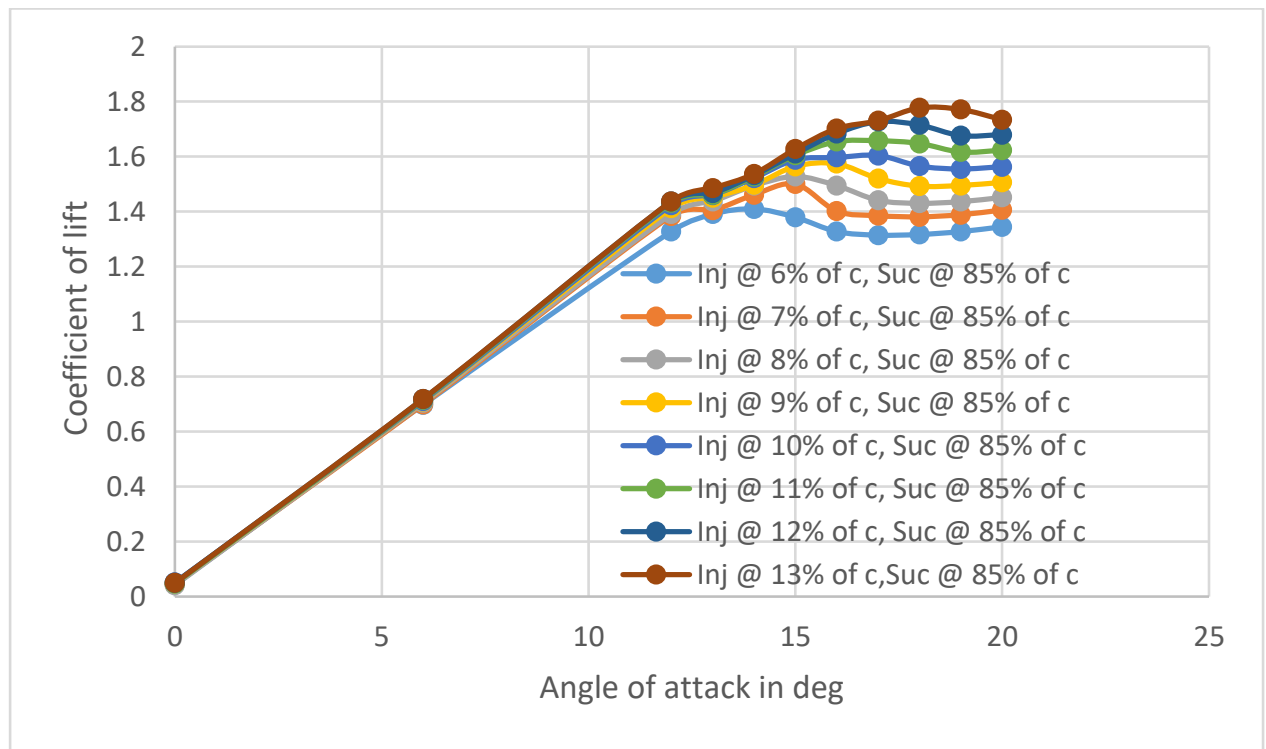




\section{Figure 8(b)}

\section{Drag Coefficient vs AoA}

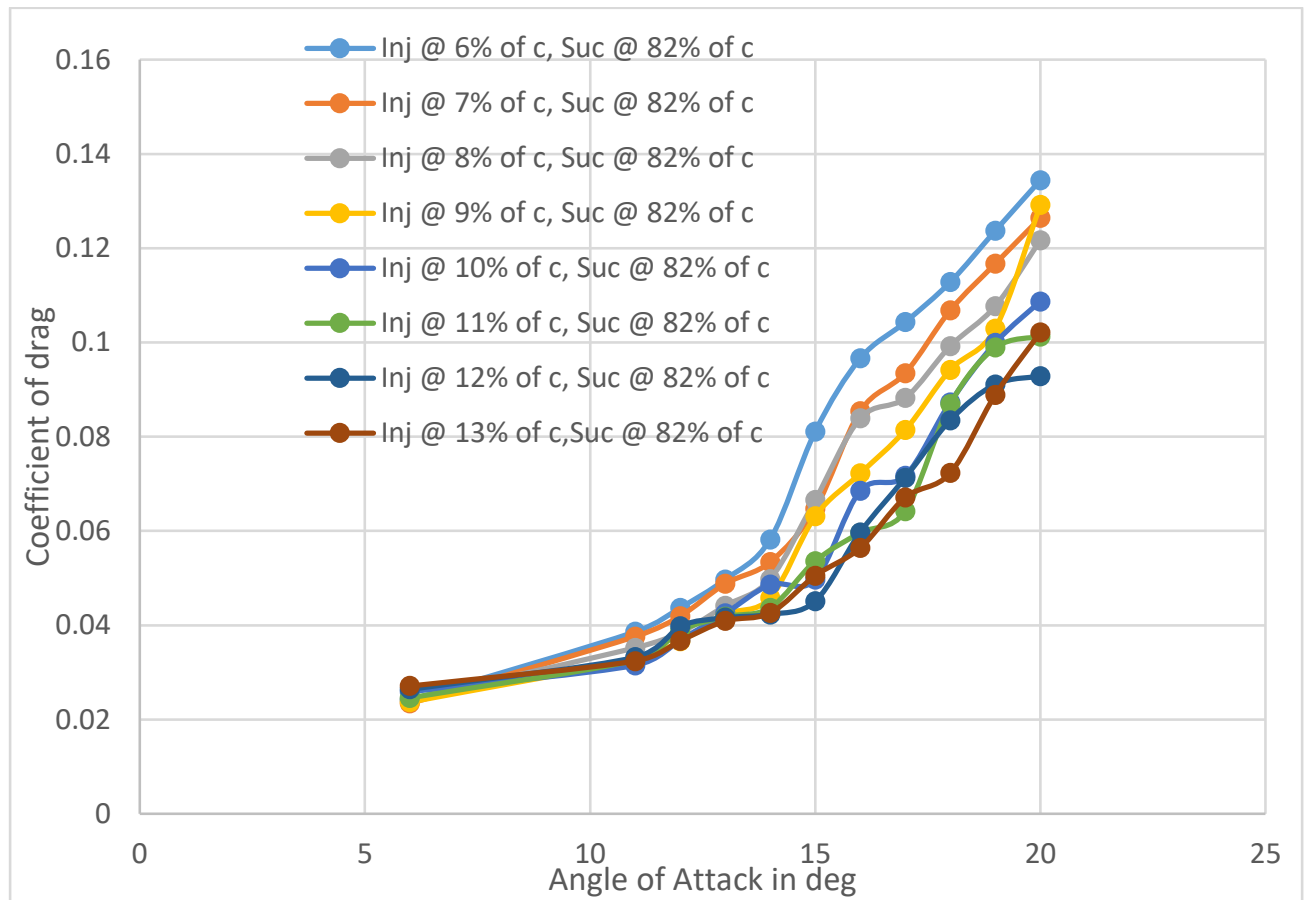

Note. The comparison of Lift coefficient and Drag coefficient of CFJ airfoil for all design specification (varying injection slot location from $6 \%$ to $13 \%$ of chord and suction slot at $85 \%$ of c).

\section{Figure 9}

The Comparison of Lift Coefficient for the Injection Slot at 10\% of the Chord and Suction Slot at $82 \%$ and $85 \%$ of Chord 


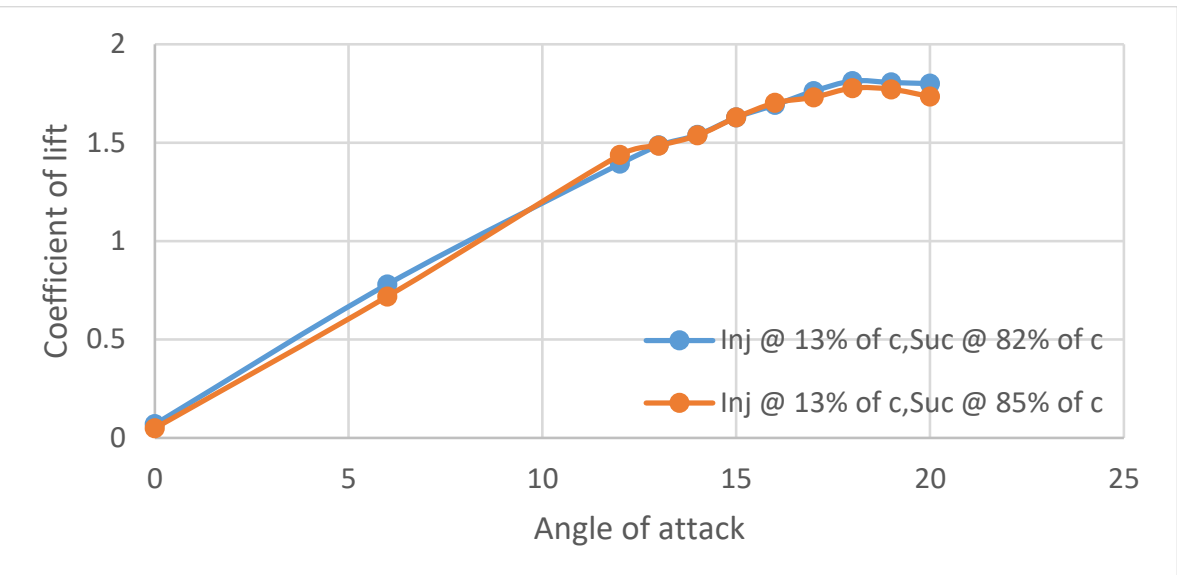

Conclusion

The present study has numerically investigated the effect of the CFJ mechanism in the airfoil. The results from the analysis are proved that the CFJ airfoil will produce more lift coefficient than the baseline airfoil. This is because the downstream gets energized due to the injection air. So that the airflow remains attached over to the body, and it increases the lift coefficient. The effect of the location of the injection and suction slots on CFJ airfoil performance are also studied successfully. The result indicated that the lift coefficient is increasing by varying the injection slot location away from the leading edge for fixed suction slot location. On one hand, a percentage of increase in maximum lift coefficient of CFJ airfoil compares to the baseline airfoil is varying from $3.6 \%$ to $31.9 \%$ for an injection slot location varying from $6 \%$ to $13 \%$ of chord and suction slot fixed at $82 \%$ of chord. On other hand, a percentage of increase in maximum lift coefficient of CFJ airfoil compares to the baseline airfoil is variying from $2.58 \%$ to $29.32 \%$ for an injection slot location varying from $6 \%$ to $13 \%$ of chord and suction slot fixed at $85 \%$ of chord. Keeping the structural aspect of the wing into consideration, it's not advisable to place the injection slot far away from the leading edge of an airfoil. To reduce the workload of pump, the suction slot has to located, where the pressure of the airflow over the top surface of the airfoil is maximum Based on the structure and implementation complexity, the location of the injection and suction slot has to be fixed. (It cannot be placed arbitrarily). In the future, the work will be carried out to investigate the effect of the height of injection and suction slots, injection mass flow rate, and free stream mach number on the performance of CFJ airfoil. 


\section{References}

Abinav, R., Nair, N. R., Sravan, P., Kumar, P., \& Nagaraja, S. R. (2016). CFD analysis of co flow jet airfoil. Indian Journal of Science and Technology, 9,45 .

Balaji, K., \& G Jims, J. J. (2020). Experimental investigations on the performance of a modified co-flow jet aerofoil. Indian Journal of Science and Technology, 13(19), 1873-1881. doi:10.17485/IJST/v13i19.85

Ethiraj, S. (2017). Aerodynamic performance analysis of a co-flow jet aerofoil using CFD. IRJET, 4(7), 987-993.

Hossain, A., Uddin, N., Islam, R., \& Mashud, M. (2015) Enhancement of aerodynamic properties of an airfoil by co flow jet (CFJ) flow. American Journal of Engineering Research, 4, 1.

Jacobs, E., \& Sherman A. (1937). Airfoil section characteristics as affected by variations of the Reynolds number. Report number NACA-TR-586. https://ntrs.nasa.gov/citations/19930091662

Khoshnevis, A. B., Yazdani, S., \& Salimipour, E (2020). Analysis of co flow jet effects on airfoil at moderate Reynolds number. Journal of Theoretical and Applied Mechanics 58(3):685-695. doi:10.15632/jtam-pl/122266

Matthews, M. (2017). Co-flow jet (CFJ) airfoils practicality in engineless airplanes. https://digitalworks.union.edu/cgi/ viewcontent.cgi? article $=1057 \&$ context $=$ theses

Siddanathi, S. L. (2016). Application of coflow jet concept to aircraft lift increase. IJAMAE, 3(1), 24-27.

Zha, G., \& Paxton, C. D. (2004). A novel airfoil circulation augment flow control method using co-flow jet. 2nd AIAA Flow Control Conference, Portland, Oregon.

Zha, G., Gao, W., \& Paxton, C. D. (2007). Jet effects on coflow jet airfoil performance. AIAA Journal, 45, 6, 1222-1231.

Zha, G., Paxton, C. D., Conley, C. A., Wells, A., \& Carroll, B. F. (2006). Effect of injection slot size on the performance of coflow jet airfoil. Journal of Aircraft, 43, 4, 987-995. 


\section{Table 1}

\section{Appendix A}

CFD Results ( $C_{l}$ vs AoA) of CFJ Airfoil for Location of Injection Slot Varies from 6\% to $13 \%$ of $c$ and Suction Slot at $82 \%$ of $\mathrm{c}$

\begin{tabular}{|c|c|c|c|c|c|c|c|c|}
\hline $\begin{array}{c}\text { AoA } \\
\text { (deg) }\end{array}$ & $\begin{array}{c}\text { Inj @ 6\% } \\
\text { of c }\end{array}$ & $\begin{array}{c}\text { Inj @ 7\% } \\
\text { of c }\end{array}$ & $\begin{array}{c}\text { Inj @ 8\% } \\
\text { of c }\end{array}$ & $\begin{array}{c}\text { Inj @ 9\% } \\
\text { of c }\end{array}$ & $\begin{array}{c}\text { Inj @ 10\% } \\
\text { of c } \\
\text { Inj @ 11\% } \\
\text { of c }\end{array}$ & $\begin{array}{c}\text { Inj @ 12\% } \\
\text { of c }\end{array}$ & $\begin{array}{c}\text { Inj @ 13\% } \\
\text { of c }\end{array}$ \\
\hline 0 & 0.0542 & 0.0559 & .0549 & 0.0612 & 0.0609 & 0.0624 & 0.0678 & 0.0694 \\
\hline 6 & 0.7253 & 0.7294 & .7311 & 0.7424 & 0.7512 & 0.7644 & 0.7713 & 0.7804 \\
\hline 11 & 1.2408 & 1.2546 & .2616 & 1.2573 & 1.2859 & 1.2369 & 1.2985 & 1.2859 \\
\hline 12 & 1.3173 & 1.3335 & .3445 & 1.3472 & 1.3596 & 1.3423 & 1.3876 & 1.3927 \\
\hline 13 & 1.3774 & 1.4143 & .4223 & 1.4286 & 1.4125 & 1.4265 & 1.4758 & 1.4863 \\
\hline 14 & 1.4094 & 1.4629 & .4832 & 1.4971 & 1.5241 & 1.5255 & 1.5343 & 1.5395 \\
\hline 15 & 1.4238 & 1.5016 & .5726 & 1.5937 & 1.5708 & 1.5958 & 1.5976 & 1.6281 \\
\hline 16 & 1.3859 & 1.4748 & .5636 & 1.6083 & 1.6498 & 1.6471 & 1.6851 & 1.6921 \\
\hline 17 & 1.3297 & 1.4251 & .4651 & 1.5927 & 1.6209 & 1.6964 & 1.7687 & 1.7616 \\
\hline 18 & 1.3312 & 1.4124 & .4632 & 1.5349 & 1.5954 & 1.7189 & 1.7431 & 1.8135 \\
\hline 19 & 1.3379 & 1.4015 & .4534 & 1.5272 & 1.5879 & 1.6713 & 1.7572 & 1.8058 \\
\hline 20 & 1.3515 & 1.4146 & .4398 & 1.5248 & 1.5838 & 1.6374 & 1.6908 & 1.8005 \\
\hline
\end{tabular}


International Journal of Aviation, Aeronautics, and Aerospace, Vol. 8 [2021], Iss. 1, Art. 10

Table 2

CFD Results ( $C_{d}$ vs AoA) of CFJ Airfoil for Location of Injection Slot Varies From 6\% to $13 \%$ of c and Suction Slot at $82 \%$ of $c$

\begin{tabular}{|c|c|c|c|c|c|c|c|c|}
\hline $\begin{array}{l}\text { AoA } \\
(\text { deg) }\end{array}$ & $\begin{array}{c}\text { Inj @ 6\% } \\
\text { of c }\end{array}$ & $\begin{array}{c}\text { Inj @ 7\% } \\
\text { of c }\end{array}$ & $\begin{array}{c}\text { Inj @ 8\% } \\
\text { of c }\end{array}$ & $\begin{array}{c}\text { Inj @ 9\% } \\
\text { of c }\end{array}$ & $\begin{array}{c}\text { Inj @ } 10 \% \\
\text { of c }\end{array}$ & $\begin{array}{c}\text { Inj @ } 11 \% \\
\text { of c }\end{array}$ & $\begin{array}{c}\text { Inj @ } 12 \% \\
\text { of c }\end{array}$ & $\begin{array}{c}\text { Inj @ } 13 \% \\
\text { of c }\end{array}$ \\
\hline 0 & 0.0201 & 0.0199 & 0.01994 & 0.0204 & 0.0201 & 0.0199 & 0.0203 & 0.0204 \\
\hline 6 & 0.0241 & 0.0234 & 0.0243 & 0.0237 & 0.0259 & 0.0246 & 0.0264 & 0.0271 \\
\hline 11 & 0.0386 & 0.0376 & 0.0352 & 0.0327 & 0.0315 & 0.0326 & 0.0332 & 0.0324 \\
\hline 12 & 0.0437 & 0.0419 & 0.0384 & 0.0366 & 0.0369 & 0.0389 & 0.0398 & 0.0367 \\
\hline 13 & 0.0497 & 0.0488 & 0.0441 & 0.0423 & 0.0425 & 0.0418 & 0.0416 & 0.0409 \\
\hline 14 & 0.0582 & 0.0534 & 0.0498 & 0.0458 & 0.0486 & 0.0437 & 0.0423 & 0.0426 \\
\hline 15 & 0.0811 & 0.0647 & 0.0666 & 0.0631 & 0.0497 & 0.0536 & 0.0451 & 0.0505 \\
\hline 16 & 0.0966 & 0.0854 & 0.0839 & 0.0722 & 0.0685 & 0.0596 & 0.0597 & 0.0564 \\
\hline 17 & 0.1043 & 0.0935 & 0.0882 & 0.0814 & 0.0717 & 0.0642 & 0.0767 & 0.0671 \\
\hline 18 & 0.1128 & 0.1068 & 0.0992 & 0.0942 & 0.0873 & 0.0869 & 0.0815 & 0.0723 \\
\hline 19 & 0.1237 & 0.1167 & 0.1077 & 0.1029 & 0.0999 & 0.0989 & 0.0911 & 0.0889 \\
\hline 20 & 0.1344 & 0.1264 & 0.1217 & 0.1292 & 0.1087 & 0.1012 & 0.0928 & 0.1021 \\
\hline
\end{tabular}


Table 3

CFD Results ( $C_{l}$ vs AoA) of CFJ Airfoil for Location of Injection Slot Varies From 6\% to $13 \%$ of $c$ and Suction Slot at $85 \%$ of $c$

\begin{tabular}{|c|c|c|c|c|c|c|c|c|}
\hline $\begin{array}{l}\text { AoA } \\
(\mathrm{deg})\end{array}$ & $\begin{array}{c}\text { Inj @6\% } \\
\text { of c }\end{array}$ & $\begin{array}{c}\text { Inj @ 7\% } \\
\text { of c }\end{array}$ & $\begin{array}{c}\text { Inj @ 8\% } \\
\text { of c }\end{array}$ & $\begin{array}{c}\text { Inj @ 9\% } \\
\text { of c }\end{array}$ & $\begin{array}{c}\text { Inj @ } 10 \% \\
\text { of c }\end{array}$ & $\begin{array}{c}\text { Inj } @ 11 \% \\
\text { of } \mathrm{c}\end{array}$ & $\begin{array}{c}\text { Inj @ } 12 \% \\
\text { of c }\end{array}$ & $\begin{array}{c}\text { Inj @ 13\% } \\
\text { of c }\end{array}$ \\
\hline 0 & 0.0434 & 0.0447 & 0.0412 & 0.0484 & 0.0512 & 0.0472 & 0.0501 & 0.0495 \\
\hline 6 & 0.6978 & 0.6991 & 0.7045 & 0.7091 & 0.7112 & 0.7152 & 0.7184 & 0.7191 \\
\hline 12 & 1.3279 & 0.3845 & 1.3914 & 0.4121 & 1.4239 & 1.4317 & 1.4364 & 1.4375 \\
\hline 13 & 1.3909 & 0.4051 & 1.4374 & 0.4512 & 1.4598 & 1.4613 & 1.4671 & 1.4851 \\
\hline 14 & 1.4098 & 0.4615 & 1.4946 & 0.4969 & 1.5223 & 1.5277 & 1.5321 & 1.5371 \\
\hline 15 & 1.3795 & 0.5003 & 1.5277 & 0.5647 & 1.5886 & 1.6044 & 1.6108 & 1.6279 \\
\hline 16 & 1.3274 & 0.4019 & 1.4949 & 0.5741 & 1.5971 & 1.6546 & 1.6841 & 1.7021 \\
\hline 17 & 1.3146 & 0.3853 & 1.4412 & 0.5204 & 1.6043 & 1.6577 & 1.7273 & 1.7304 \\
\hline 18 & 1.3169 & 0.3812 & 1.4304 & 10.4926 & 1.5656 & 1.6481 & 1.7151 & 1.7773 \\
\hline 19 & 1.3274 & 0.3887 & 1.4363 & 0.4952 & 1.5552 & 1.6166 & 1.6763 & 1.7715 \\
\hline 20 & 1.3451 & 0.406 & 1.4517 & 0.5064 & 1.5634 & 1.6233 & 1.6799 & 1.7344 \\
\hline
\end{tabular}


International Journal of Aviation, Aeronautics, and Aerospace, Vol. 8 [2021], Iss. 1, Art. 10

Table 4

CFD Results ( $C_{d}$ vs AoA) of CFJ Airfoil for Location of Injection Slot Varies from 6\% to $13 \%$ of $c$ and Suction Slot at $85 \%$ of $c$

\begin{tabular}{|c|c|c|c|c|c|c|c|c|}
\hline $\begin{array}{c}\text { AoA } \\
\text { (deg) }\end{array}$ & $\begin{array}{c}\text { Inj @ 6\% } \\
\text { of c }\end{array}$ & $\begin{array}{c}\text { Inj @ 7\% } \\
\text { of c }\end{array}$ & $\begin{array}{l}\text { Inj @ 8\% } \\
\text { of c }\end{array}$ & $\begin{array}{c}\text { Inj @ 9\% } \\
\text { of c }\end{array}$ & $\begin{array}{c}\text { Inj @ 10\% } \\
\text { of c }\end{array}$ & $\begin{array}{c}\text { Inj @ 11\% } \\
\text { of c }\end{array}$ & $\begin{array}{c}\text { Inj @ 12\% } \\
\text { of c }\end{array}$ & $\begin{array}{c}\text { Inj @ 13\% } \\
\text { of c }\end{array}$ \\
\hline 0 & 0.0201 & 0.0199 & 0.0193 & 0.0198 & 0.0241 & 0.0203 & 0.0242 & 0.0213 \\
\hline 6 & 0.0221 & 0.0227 & 0.0231 & 0.0237 & 0.0224 & 0.0229 & 0.0235 & 0.0232 \\
\hline 12 & 0.0487 & 0.0437 & 0.0422 & 0.0401 & 0.0431 & 0.0457 & 0.0406 & 0.0405 \\
\hline 13 & 0.0537 & 0.0478 & 0.0451 & 0.0427 & 0.0482 & 0.0485 & 0.0412 & 0.0413 \\
\hline 14 & 0.0615 & 0.0613 & 0.0564 & 0.0506 & 0.0491 & 0.0514 & 0.0458 & 0.0422 \\
\hline 15 & 0.0842 & 0.0827 & 0.0661 & 0.0607 & 0.0574 & 0.0553 & 0.0487 & 0.0449 \\
\hline 16 & 0.0928 & 0.0838 & 0.0825 & 0.0748 & 0.0668 & 0.0647 & 0.0582 & 0.0564 \\
\hline 17 & 0.1041 & 0.0976 & 0.0926 & 0.0901 & 0.0858 & 0.0749 & 0.0715 & 0.0627 \\
\hline 18 & 0.1139 & 0.1071 & 0.1019 & 0.0966 & 0.0908 & 0.0854 & 0.0834 & 0.0808 \\
\hline 19 & 0.1241 & 0.1166 & 0.1111 & 0.1056 & 0.1014 & 0.0941 & 0.0886 & 0.0852 \\
\hline 20 & 0.1346 & 0.1264 & 0.1532 & 0.1424 & 0.1091 & 0.1036 & 0.0992 & 0.0947 \\
\hline
\end{tabular}


Vigneswaran and Kumar G C: AERODYNAMIC PERFORMANCE ANALYSISOF CFJ AIRFOIL

Table 5

CFD and Experiment Results $\left(C_{l}\right.$ vs AoA) for Baseline Airfoil

\begin{tabular}{|c|c|c|}
\hline AoA $(\mathrm{deg})$ & CFJ -CFD2.3 L NODE & BASELINE - EXPRIMENT \\
\hline 0 & 0.0013 & 0 \\
\hline 1 & 0.0998 & 0.0934 \\
\hline 2 & 0.2077 & 0.2029 \\
\hline 3 & 0.3089 & 0.3013 \\
\hline 4 & 0.4119 & 0.4173 \\
\hline 5 & 0.5065 & 0.5029 \\
\hline 6 & 0.6141 & 0.6149 \\
\hline 7 & 0.7106 & 0.7134 \\
\hline 8 & 0.8046 & 0.7754 \\
\hline 9 & 0.9048 & 0.9018 \\
\hline 10 & 0.9887 & 0.9673 \\
\hline 11 & 1.0742 & 1.0127 \\
\hline 12 & 1.1515 & 1.0551 \\
\hline 13 & 1.2251 & 1.1554 \\
\hline 14 & 1.2855 & 1.1863 \\
\hline 15 & 1.3322 & 1.2136 \\
\hline 16 & 1.3687 & 1.2274 \\
\hline 17 & 1.3743 & 1.1873 \\
\hline 18 & 1.2399 & 1.1536 \\
\hline 19 & 1.2223 & 1.0934 \\
\hline
\end{tabular}


Table 6

CFD and Experiment Results $\left(C_{d} v s\right.$ AoA) for Baseline Airfoil

\begin{tabular}{|c|c|c|}
\hline AoA (deg) & CFJ -CFD2.3 L NODE & BASELINE - EXPRIMENT \\
\hline 0 & 0.0012 & 0 \\
\hline 1 & 0.0147 & 0.0087 \\
\hline 2 & 0.0149 & 0.0129 \\
\hline 3 & 0.0154 & 0.0131 \\
\hline 4 & 0.0161 & 0.0138 \\
\hline 5 & 0.0163 & 0.0141 \\
\hline 6 & 0.0186 & 0.0152 \\
\hline 7 & 0.0196 & 0.0163 \\
\hline 8 & 0.0222 & 0.0177 \\
\hline 9 & 0.0235 & 0.0193 \\
\hline 10 & 0.0269 & 0.0202 \\
\hline 11 & 0.0293 & 0.0221 \\
\hline 12 & 0.0318 & 0.0244 \\
\hline 13 & 0.0375 & 0.0298 \\
\hline 14 & 0.0394 & 0.0308 \\
\hline 15 & 0.0498 & 0.0397 \\
\hline 16 & 0.0596 & 0.0587 \\
\hline 17 & 0.0709 & 0.0697 \\
\hline 18 & 0.0864 & 0.0785 \\
\hline 19 & 0.1231 & 0.0918 \\
\hline
\end{tabular}

